\title{
Effects of Ramp Rate and Starting Temperature on Gas Chromatography-Mass Spectrometric Analyses of Petroleum Hydrocarbons
}

\author{
S. U. Oghoje, ${ }^{1,2}{ }^{2}$, J. E. Ukpebor ${ }^{2}$, P. O. Agbaire ${ }^{1}$, C. Ejeomo ${ }^{3}$ and P. O. Oviasogie ${ }^{4}$ \\ ${ }^{1}$ Department of Chemistry, Faculty of Science, Delta State University, PMB 1, Abraka, Delta State, \\ Nigeria \\ ${ }^{2}$ Department of Chemistry, Faculty of Physical Sciences, University of Benin, PMB 1154, Benin City, \\ Edo State, Nigeria \\ ${ }^{3}$ Department of Chemistry, Faculty of Sciences, Michael and Cecelia University, Agbara-Otor, Delta \\ State, Nigeria \\ ${ }^{4}$ Nigeria Institute of Oil Palm Research, NIFOR, Benin Cities, Edo State, Nigeria \\ *Corresponding author, oghojesteve@yahoo.com \\ Received 30 July 2020; accepted 30 October 2020, published online 03 November 2020
}

\begin{abstract}
The quest for better GC-MS/FID starting temperature and ramping conditions for the quantification of hydrocarbons in our environment necessitated this study. A surrogate n-alkane standard was screened using nine GC-MS conditions involving the alteration of ramp rates and/or initial temperatures. There was observed increase in the TIC chromatogram or ionic mass unit as the ramp rate or initial temperatures were increased. The peak areas of the analytes were significantly affected. The $\mathrm{R}^{2}$ and response factor values of the eight standard calibration curves (each for a modified method) varied from $0.9224-0.9971$ and $0.0034-0.0045$ respectively. Consequently, the quantification of the diesel concentration in diesel spiked water and soil by using the eight methods was different from each other and from the standard method. Average differences of 11.5 and $15 \%$ from the theoretical values were observed for the water and soil analyses respectively. Increasing ramp rates or initial temperatures led to shorter throughput but less data accuracy. The use of $60{ }^{\circ} \mathrm{C}$ as starting temperature and ramp at $5{ }^{\circ} \mathrm{C} /$ minute was better for quantification of the diesel range organics.

Key words: Methods modification, Gas Chromatograph-Mass Spectrometric analyses, Petroleum Hydrocarbons
\end{abstract}

\section{Introduction}

The Gas Chromatography-Mass Spectrometer is a very sensitive and robust spectrometric instrument for the evaluation of the quality and quantity of various organic compounds including the petroleum hydrocarbons in the environment. The use of the instrument involves proper adjustment, control and monitoring of some basic parameters such as the ramp rate and initial temperature which could affects its analytical performance. The United State Environmental Pretention Agency (USEPA 1994) recommended initial temperature of $40{ }^{\circ} \mathrm{C}$ and ramp rate of $5{ }^{\circ} \mathrm{C} /$ minute for the analyses of the diesel Range Organic (DRO). Recently, the discrepancy in analytical results method specified type 4 column for DRO analyses. The other screening conditions for this standard method are stated in Table 1. To determine both the total quantity of pollutants on some oil polluted samples send to three laboratories was reported [1]. The researchers presumed the differences observed to be due to different laboratory equipment and instrumental conditions which may include the screening conditions of the GC-MS/FID used by the analysts [1]. "Users, government laboratories and private laboratories sometimes disagree on the scope, range of application and quality of information obtained from using different methods" [2]. Analysis of DRO by United State Environmental Protection Agency (USEPA) methods, 8015,[3] or modified USEPA method 8015B [4] is a commonplace in most environmental analytical laboratories. The and the composition such as petroleum oils in the soil, an efficient instrumental procedure should be followed. This is more so when the allowable amount of a pollutant in an 
environmental matrix is very small. For instance, the maximum allowable contamination level of BTEX (benzene, toluene, ethyl benzene and xylene) in drinking water (in ppm) is 0.005 , $2.0,0.66$ and 0.44 respectively [5]. Thus, the importance of using appropriate GC-MS/FID screening condition for BTEX and indeed total hydrocarbon analyses cannot be overemphasised. Following the USEPA specifications [3], it would take about 55 minutes to complete the GC-MS screening of samples for DRO analysis. In attempts to achieve shorter throughput periods, several laboratories have resorted to increasing ramp rate and/or starting temperature. The key to such aim is a method that is both fast and robust, allowing the laboratory to achieve shorter analysis time and at lowest cost.

Table 1: USEPA method 8015, GC-MS/FID screening conditions [3]

\begin{tabular}{ll}
\hline Column 4 type: & Column 4 (DROs)x \\
Carrier gas (Helium) flow rate: & $5-7 \mathrm{~mL} /$ minute \\
Make up gas (Helium) flow rate: & $30 \mathrm{~mL} / \mathrm{min}$ \\
Injector temperature: & $200{ }^{\circ} \mathrm{C}$ \\
Detector temperature: & $340{ }^{\circ} \mathrm{C}$ \\
\hline & Temperature program \\
\hline Initial temperature: & $45^{\circ} \mathrm{C}$, hold 3 minute \\
Program: & $45^{\circ} \mathrm{C}$ to $275^{\circ} \mathrm{C}$ at $12{ }^{\circ} \mathrm{C} / \mathrm{min}$ \\
Final temperature & $275^{\circ} \mathrm{C}$, hold 12 min \\
\hline
\end{tabular}

Some studies have shown the effects of ramp rate and temperature on the throughput period of GC-MS/FID analyses [6]. Ferna'ndez et al [6] carried out GC-FID analysis of diesel spiked soil at initial temperature and ramp rate of $60{ }^{\circ} \mathrm{C}$ and $5{ }^{\circ} \mathrm{C}$ /minute. They used about 50 minutes to complete analysis of a sample. In a similar analysis, Paula et al [13] used initial temperature of $40{ }^{\circ} \mathrm{C}$ and ramp rate of $5{ }^{\circ} \mathrm{C} /$ minute and got a throughput period of about 55 minutes per sample. In order to run a similar analysis at a shorter throughput, Corte et al [2] used starting temperature of $40{ }^{\circ} \mathrm{C}$ and increased ramp rate to $15^{\circ} \mathrm{C} /$ minute and they completed the analysis in less than 30 minutes per sample. Similarly, Rauckyte, et al used modified USEPA method $8015 \mathrm{~B}$, using initial temperature of $45^{\circ} \mathrm{C}$ and ramp rate of $12{ }^{\circ} \mathrm{C} /$ minute and they completed the analysis of DRO sample at less than 35 minutes [14]. Throughput periods of less than 20 minutes per sample using the oven technology have been advertised by GC-MS/FID manufacturers [7]. Ramp rate and initial temperature are important parameters in gas chromatographic - mass spectrometric (GCMS/FID) analyses. Adjustment of these parameters could have analytical implication on the retention time indices and fragmentation pattern as well as quantification of organic compounds. Retention time $\left(t_{R}\right)$ relates to the column temperature by the equation:[8]

$\boldsymbol{t}_{R=L(k+1) / \mathrm{u}}$

Where $\mathrm{k}$ is the solute capacity ratio (capacity factor, retention factor),

$\mathrm{L}$ is the column length and $\overline{\mathrm{u}}$ is the average carrier gas velocity.

The value of retention factor is related to column temperature $(\mathrm{Tc})$ by

$\operatorname{In}^{K}=\left(\frac{A}{T_{c}}\right)+B$

Where constants $\mathrm{A}$ and $\mathrm{B}$ have unique values for every compound and every stationary phase type and phase volume ratio [8]

Diesel is a petroleum mixture containing about 18 hydrocarbons ranging mainly from decane (C10) to octacosane (C28) [4]. As a mixture, its boiling point varies $170-430{ }^{\circ} \mathrm{C}[4,15,16]$. The DRO are prominent members of petro-oil contaminants in the environment [17].

The GC-MS/FID identification and quantification of organic substances including the DRO is common and have been very successful. Qualifications of the unknown DRO involve the study of the fragmentation pattern and identification of the $\mathrm{M}^{+}$fragments and calculation of retention time indices (e.g Kovats retention index) of individual member $[8,20$, 21]. On the other hand, quantification analyses 
involve the integration of the area under the individual compound peaks (i.e. peak area) [18]. Sometime, Internal standard (IS) is introduced during the GC-MS/FID analysis and the peak area ratio (peak area of the analyte/peak /area of (IS) is calculated and applied for the standard calibration [18]. Some electronic programmes such as the Thermo X CaliburQual browser have been developed to achieve this [22]. The pattern in a chromatogram emerged as a decisive factor of qualitative analysis. Preliminary identifications were made by visual comparison of chromatogram profiles between the unknown and a set of standards prior to calculation of Kovats or relative retention index for each component. Increasing the starting temperature and ramp rate may affect the fragmentation pattern of DRO. Qualitatively, GC-MS analyses of DRO in all environmental matrices involve identification of the mass of the $\mathrm{M}^{+}$fractions from the mass spectra. Sometimes, the relative abundance of this fragment could be very small and may be overshadowed by background noise thereby making its identification somehow difficult visually. To ease the identification, the mass spectrum is exported to standard mass spectrometric data base such as by The National Institute of Standards and Technology (NIST) where it is automatically matched with existing similar mass spectra in the data base $[19,20]$. The analyst is then left to consider the best match. The approach may give room for subjectivity and probability. It is often difficult to find exact match. This may be due to the different GC-MS/FID screening conditions from which the standard spectrometric data were generated. A better knowledge of how DRO fragmentation relates to GC-MS/FID screening conditions may ameliorate the difficulties researchers often encounter in the course of identifying DRO or organic compounds in environmental matrices.

At a starting temperature of $100{ }^{\circ} \mathrm{C}$ and ramp rate of $10{ }^{\circ} \mathrm{C} /$ minute, it would take about 25 minutes (as investigated in this study) to complete a similar analysis reported by Corte et al (mentioned earlier) [2]. This could save the life span of GC-MS machine and make such analyses time saving and more economical. However, shorter retention time would obviously, be expected for every hydrocarbon present when compared to the method used by Ferna'ndez et al [6]. In this study, we investigated the extent to which the use of different ramp rates and starting temperatures could affect spectrometric qualification and quantification of the DRO. Eight GC-MS different screening conditions involving adjustment of the initial temperatures and ramp rates were evaluated with the view to assessing their effects on the fragmentation pattern of individual DRO. Also assessed, is the effects of the environmental matrices from which the DRO were extracted on their fragmentation pattern. The unique fragmentation of DRO compound may be a symbol of its identity. Every compound has specific GC-MS retention time or index but this depends on the nature of the GC machine and the status of the column as well as the screening conditions $[8,19,20]$. The fragmentation pattern is also unique for families of compounds [19, 20, 21]. Therefore, a good knowledge of the fragmentation of a compound in GC-MS analyses could be a useful aid in identifying the presence of such compound in a given environmental matrix by GC-MS/FID analyses. In this study, we specifically aimed at: 1) evaluating the effects of increasing starting temperature and/or ramp rate on the fragmentation pattern of petro-genic diesel compounds. 2) assess how $\mathrm{sta}_{\mathrm{rt}}$ ing temperature and ramp rate relate to quantification of DRO by GC-MS and 3) compare the accuracy of quantification of DRO (in water and soil) by the 8 modified methods to that of standard USEPA Method 8015B.

\section{Materials and methods}

Two Surrogate standards of DRO (containing $1000 \mu \mathrm{g} / \mathrm{ml} 16$ or 21 DRO compounds were purchased. The first surrogate hereafter refers to as SStd 1 was supplied by Restek Plc Bellefonte, and the second surrogate hereafter refer to as SStd 2 was purchased from Sigma-Aldrich Plc. UK. The said standards have been certified by Restek and Supelco laboratories respectively. According to the certificate of analysis, SStd 1 and SStd 2 contain $1000 \mu \mathrm{g} / \mathrm{ml}$ each of saturated alkanes $\mathrm{C} 10-\mathrm{C} 25$ and $\mathrm{C} 7-\mathrm{C} 30$ respectively. Their GC-MS chromatograms as well as the conditions of analyses and certificate of analysis 
were contained in the literatures that accompanied the standards. The SStd 1 was used to assess the effects of the different GC-MS screening conditions on the qualification and peak area of DRO compounds while SStd2 was used as calibration reference to evaluate the effects of the 8 GC-MS screening conditions and US ES EPA method 8015B on quantification of DRO in diesel spiked water and soil. Commercial diesel (branded ESSO) was procured from a local petrol station in Bangor Gwynedd, sharp sand soil (branded as washed sharp sand) was obtained from B and Q Plc. Bangor Gwynedd; de-ionized water was obtained locally from School of Chemistry, Bangor University, Bangor Gwynedd, all in the United Kingdom (UK) and 1,3,5 trichlorobenzene (TCB) and dichloromethame (DCM), HPLG grade were bought from SigmaAldrich plc.,UK. 1,3,5 trichlorobenzene was used as the suitable internal standard because its retention time does not overlap with those of the samples The experimental work was carried out at the School of Chemistry laboratory, Bangor University, Bangor Gwynedd, North Wales, UK.

\section{The use of Internal Standard}

1,3,5 trichlorobenzene was used as the suitable internal standard because its retention time does not overlap with those of the DRO. The internal standard $(25 \mathrm{~g})$ was dissolved in $250 \mathrm{ml}$ of $\mathrm{n}$ hexane or DCM $1 \mathrm{dm}^{3}$ volumetric flask and made up to mark with the solvent. The n- hexane form was used in the preparation of the SStd 1 standard solutions while the DCM form is used in the preparation of the SStd 2 standard calibration solutions [9].

\section{Samples treatment and extraction}

\section{Soil:}

The soil was air dried under ambient laboratory conditions and passed through $2 \mathrm{~mm}$ sieve. Then $10 \mathrm{~g}(12,246 \mu \mathrm{l})$ diesel (of density $0.81 \mathrm{~g} / \mathrm{cm}$ ) was added to $250 \mathrm{ml}$ of petroleum spirit in 1 litre volumetric flask and made up to mark as the spiking solution. $100 \mathrm{ml}$ of the spiking solution was then added to $10 \mathrm{~g}$ of soil in $250 \mathrm{ml}$ beaker. A blank sample was also made by measuring same volume into a pre-weighed beaker. Both samples were prepared in triplicates and were kept in a fume cupboard overnight for the petroleum spirit to evaporate completely. The blank samples were re-weighed as a control to ascertain the actual diesel left in the soil after the evaporation of the spirit. Both the soil and the blanks samples were then gently extracted by Vortex method [13] for 1 hour each using $30 \mathrm{ml}$ DCM as the extracting solvent. The mixtures were passed through Fisher brand $(150 \mathrm{~mm})$ filter paper and each residue was washed twice with additional $10 \mathrm{ml}$ (each time) of the extracting solvent. The extracts were combined accordingly in a $50 \mathrm{ml}$ volumetric flask and made up to mark with the extracting solvent The extracts were then filled into $1 \mathrm{ml}$ GC-MS vials for analyses by the nine selected GC-MS screening conditions including the USEPA method 8015B (Table 2) after adding $0.65 \mathrm{~g}$ of TCB as internal standard

Table 2: The eight modified GC-MS screening (Used in this this study) and USEPA 8015B Methods [4]

\begin{tabular}{|c|c|c|c|}
\hline $\begin{array}{ll}\text { GC-MS } & \text { Screening } \\
\text { conditions (SC) } & \end{array}$ & Starting Temp. $\left({ }^{\circ} \mathrm{C}\right)$ & Ramp rate $\left({ }^{\circ} \mathrm{C} / \mathrm{min}\right)$ & Final Temp. $\left({ }^{\circ} \mathrm{C}\right)$ \\
\hline $1(\mathrm{SC} 1)$ & 40 & 5 & 300 \\
\hline $2(\mathrm{SC} 2)$ & 40 & 10 & 300 \\
\hline $3(\mathrm{SC} 3)$ & 60 & 5 & 300 \\
\hline $4(\mathrm{SC} 4)$ & 60 & 10 & 300 \\
\hline $5(\mathrm{SC} 5)$ & 80 & 5 & 300 \\
\hline $6(\mathrm{SC} 6)$ & 80 & 10 & 300 \\
\hline 7 (SC 7) & 100 & 5 & 300 \\
\hline $8(\mathrm{SC} 8)$ & 100 & 10 & 300 \\
\hline US EPA Method 8015B [4] & 45 & 12 & 275 \\
\hline
\end{tabular}




\section{Water samples}

$100 \mathrm{ml}$ of de-ionized water was measured into $250 \mathrm{ml}$ conical flask. $1 \mathrm{~g}(1,235 \mu \mathrm{l}$ ) diesel (of density $0.81 \mathrm{~g} / \mathrm{cm}$ ) was added. The samples were prepared in 3 triplicates and left on the bench top for 1 hour to stabilize. At the end of the period, they were poured into different separating funnels. To each funnel was added $40 \mathrm{ml}$ of the extracting solvent and shaken vigorously for 5 minutes and clamped to rest. After 15 minutes rest, the aqueous layer was separated and reextracted twice with $10 \mathrm{ml}$ each of the extracting solvent. The three portions (DCM) extract) were added up and $5 \mathrm{~g}$ of sodium sulphate was added to the extract; shaken vigorously for about 3 minutes and passed through a Fisher Scientific $150 \mathrm{~mm}$ brand filter paper and washed twice with additional $10 \mathrm{ml}$ (each time) of DCM. The combined extract was then made up to mark in $100 \mathrm{ml}$ volumetric flask with the extracting solvent. All the extracts were then screened (with GC-MS by the nine screening conditions (Table 2) after the addition of $1.25 \mathrm{~g}$ of TCB to each of the flask as internal standard.

\section{Analyses of samples}

\section{Qualification analyses:}

Qualification analyses of DRO by GC-MS involve the identification of individual hydrocarbon in the series $[19,20,21]$. It includes examining the GC chromatograms and the mass spectra for compounds fragmentation patterns and calculation of retention indices. In this work, the surrogate standard (SStd 1) was given $100 \%$ dilution with n-hexane and screened by the 8 GCMS screening conditions. The observed changes in the compounds fragmentation were shown in Tables 4.

\section{Quantification analyses:}

Unlike qualification analyses, GC-MS quantification of organic compounds (including the DRO) aims at specifying the quantity or concentration of an analyte in a given sample. It involves the integration of the peak area of individual compound in the GC-Mass spectra $[18,19]$. Several peak area integrating program such as the Thermo X caliburQual Browser have been developed in recent years [22]. The peak area of a compound is a direct function of its concentration in a given sample. The two variables obey leaner regression relationship such that:

$\mathrm{PA}=\mathrm{mx}+\mathrm{c}$

Where PA and $\mathrm{x}=$ peak area and concentration of the analyte respectively, $\mathrm{m}$ and $\mathrm{c}$ are the slope and intercept of the curve respectively. To minimise instrumental difference on triplicated analyses, a known compound refer to as internal standard is introduced into the extracts prior to filling the extracts into the GC-MS vials [18]. The peak area of each analyte is divided by that of the internal standard during data processing to give peak area ratio (PAR) which could be substituted into equation 3 :

$\mathrm{PAR}=\mathrm{mx}=\mathrm{c}$

In this study, the effects of 8 different GC-MS screening conditions (Table 3).on the PAR of DRO in SStd 1 were investigated

\section{Standard calibrations:}

Quantification of DRO in environmental matrices (by GC-MS analyses) includes the making of standard calibration curves from known DRO standards. From the standard curve, the values of $m$ and $c$ (equation 1 or 2) are calculated hence the amount of the analyte in a given sample [18 - 22]. From equation 2, it is obvious that any defect or change on the PAR, could equally affect the standard calibration curve and hence the quantification of the analyte. In this study, standard calibration curves were made from GC-MS screening of the same concentrations of the second surrogate standard (SStd 2) with the 8 different selected conditions and USEPA Method 8015B (Table 2). The 
summations of the PAR of the DRO were plotted against the concentrations of the corresponding standard solution. (SStd 2).

In a perfect correlation between PAR and concentration of an analyte, the correlation coefficient $\left(\mathrm{R}^{2}\right.$ value) should be 1 . However the PAR of DRO responds to concentration of DRO in the standard solution is found from the percentage of linearity as:

$\%$ linearity $=1-\left(1-R^{2}\right) \times 100$

Examination of the $\mathrm{R}^{2}$ (correlation coefficient), the slopes (or response factor) and percentage linearity values could show the best GC-MS running condition among the eight in comparison to the USEPA Method 8015B.

\section{Fragmentation pattern of DRO from different sources and concentration}

To assess the influence of sources of DRO on the fragmentation pattern of the of individual compound, extracts from diesel polluted water and soil, commercial diesel and crude oil were GC-MS screened using GC-MS condition 8 (SC 8). Different standard solutions of the commercial diesel were also made in DCM and screened with same GC-MS to assess the effects of concentration on the fragmentation of the DRO compounds. In this study, we report the results from diesel spiked soils and water

\section{Samples programming in the GC-MS used for this study}

The mode and spectrometric quality of the GCMS used in this study is enlisted in table 2. The samples were fed in the GC-MS machine and programmed for the nine screening conditions in such a way that one sample is completely screened on the nine methods before the next one. The samples were screened in one batch. The other conditions of the GCMS as stated (Table 3) was same for all the nine variable conditions.

Table 3: Other conditions of the GC-MS machine used for the analyses

\begin{tabular}{lc}
\hline GC-MS mode & Trace $1300 \mathrm{GC} / \mathrm{ITQ} 900$ Ion Trap Mass Spectrometer \\
Column type & DB 5 \\
Column size & $30 \mathrm{~m} \mathrm{x} 0.25 \mathrm{~mm}$ with $0.25 \mu \mathrm{m}$ film \\
Electron volts & $130 \mathrm{eV}$ \\
Carrier gas & Helium \\
Gas flow rate & $1.5 \mathrm{ml} / \mathrm{min}$. \\
Inlet temp. & $250{ }^{\circ} \mathrm{C}$ \\
Injection mode & $\mathrm{Split}$ \\
Split flow & $10.0 \mathrm{ml} / \mathrm{min}$. \\
Septum purge flow & $5.0 \mathrm{ml} / \mathrm{min} .:$ \\
Solvent delay & $3 \mathrm{mins}$. \\
Initial temp. holding time & $3 \mathrm{mins}$. \\
Final temp. holding time & $2 \mathrm{mins}$. \\
Trasfer line temp. & $300{ }^{\circ} \mathrm{C}$ \\
Ion source temp. & $200{ }^{\circ} \mathrm{C}$ \\
Mass range & $35-500 \mathrm{amu}$. \\
\hline
\end{tabular}

\section{Quality control and safety}

Analytical precautions were taken to ensure high quality and safety of the analyses. The standards and samples were prepared in triplicates of 3 each. The analyses were carried out in the same 
batch. The spiked soil samples were kept in the fume cupboard for evaporation of the petroleum spirit. Extraction of the soil samples were also carried out in the fume cupboard with the beakers covered with washing glasses. Gravimetric (weight) and volumetric measurement were made using four digital electronic balances and well calibrated measuring cylinders respectively. Micro-pipette (Eppendorf UK Model) was used to fill the samples extracts into the GC-MS vials with new pipette tip being used per sample. The extraction efficiency was 98.7 and 994 for the soil and water samples respectively

\section{Data analyses and statistics}

The spectrometric data were processed using Thermo X CaliburQual Browser. The processed data were then exported to Microsoft Excel version 2010 for statistical analysis. The peak area ratio was calculated as:

$\mathrm{PAR}=\mathrm{PAs} / \mathrm{PAI}$

Where PAs is the peak area of individual diesel hydrocarbon and PAI is the peak area of the internal standard.

The effect of the screening conditions on each DRO member was evaluated statistically using SSPS (one way Anova). Mean Values, Standard deviation, Standard error, relative standard deviation (RSD) and correlation coefficient for the analytical results were evaluated and calibration done using Excel program version 2010.

\section{Results and Discussion}

The aim of this analysis is to assess the effect of changing ramp rate or initial temperature on quantification of DRO in environmental matrices. It is mainly on comparing the screening conditions on the qualification and quantification of DRO. As a result, the physicochemical properties of the soil and solvent extraction efficiency of n-hexane were not reported. It is obvious that whatever quantity of DRO in the soil and water samples should be quantified similarly if the nine screening conditions were with no significant difference

\section{Retention time and Fragmentation pattern of DRO}

Retention time is a good preliminary identification property of every organic compound but it varies according to type and status of the GC machine used as well as the screening conditions. Normally, temperature affects the retention time as shown by equation 1. However, the retention time of an analyt screened under the same condition and with the same GC machine would be relatively same irrespective of the environmental sources of the compound as was the case in this study too. We observed that the retention time of each compound of the DRO in the standards and those extracted from water and soil; when screen under the same condition only varied infinitesimally. But increase in the starting temperature decreased the compounds retention time at the average of 0.20 minute per $1{ }^{\circ} \mathrm{C}$ rise in starting temperature.

As already mentioned in introduction section, fragmentation pattern of organic compounds in Mass spectroscopy is a major preliminary identification parameter [18 - 20]. Generally aliphatic alkanes show common fragmentation of $39,41,43,57,71,85$ and 99 [10] corresponding to positive ions of cyclopropene, cyclopropyl, propyl, butyl, pentyl, hexyl and heptyl respectively. However, the abundance of a fragment may vary from one alkane compound to another. The GC-MS analyses of n-alkane surrogate, commercial diesel, and extract from diesel spiked soil and water samples were carried out at initial temperature of $40^{\circ} \mathrm{C}$ and ramp rate of $10^{\circ} \mathrm{C}$ (results not shown). Other GC-MS screening conditions for this experiment were as stated (Table 3) and the fragmentation pattern of the DRO hydrocarbons were carefully evaluated. A similar exercise was also carried out with different concentration of commercial diesel. In both cases, there was no significant difference observed in the type and relative abundance of the basic fragments formed which showed that sources and concentrations of DRO have no significant effect on the fragmentation nature of the DRO hydrocarbons present. But when the surrogate standard was screened under the eight modified conditions, obvious differences were noticed among the various fragments formed. For instance, in tetradecane, 
the fragment, 41 has the highest abundance (intensity) of $100 \%$ when screened under condition 1 (SC 1) but this changed to fragment
57 when screening condition was changed to condition eight (SC 8, Figures 1 and 2, Table 4).

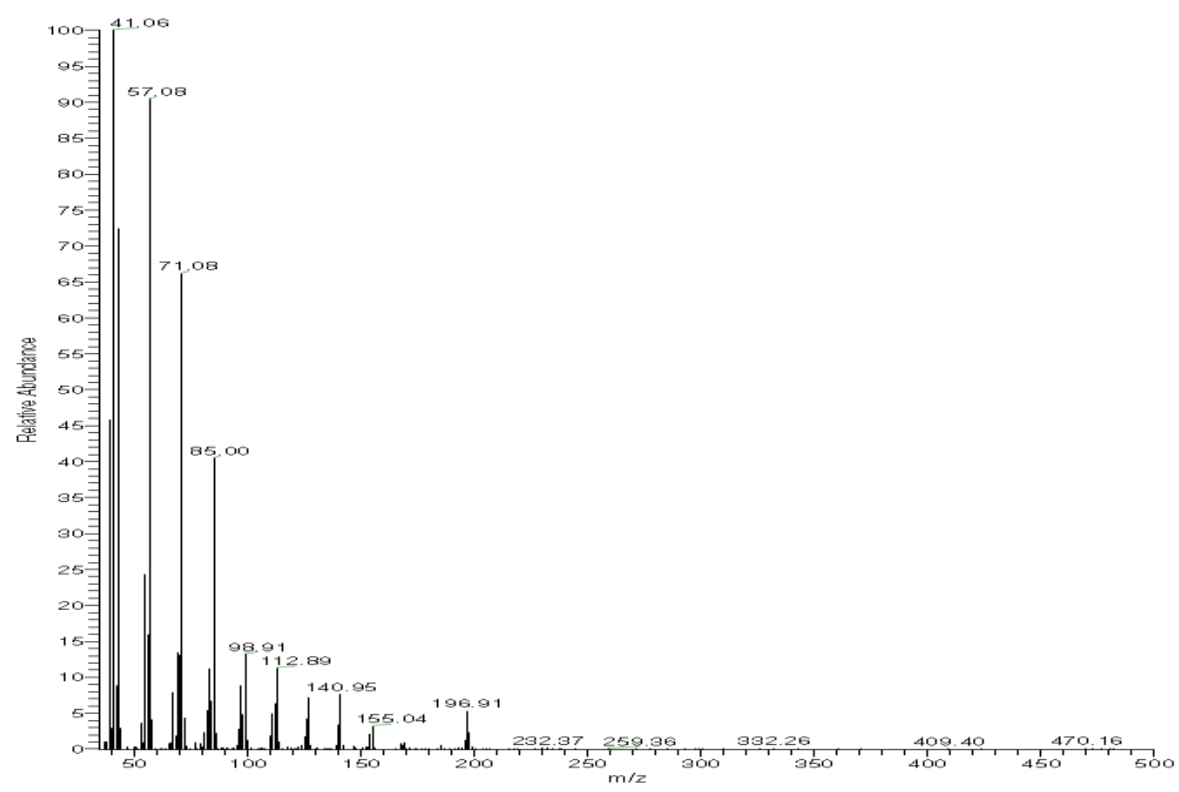

Figure 1: Mass spectrum of Tetradecane screened at ramp rate of $5{ }^{\circ} \mathrm{C} / \mathrm{min}$ and starting temperature of $40{ }^{\circ} \mathrm{C}(\mathrm{SC} 1$, Table 2)

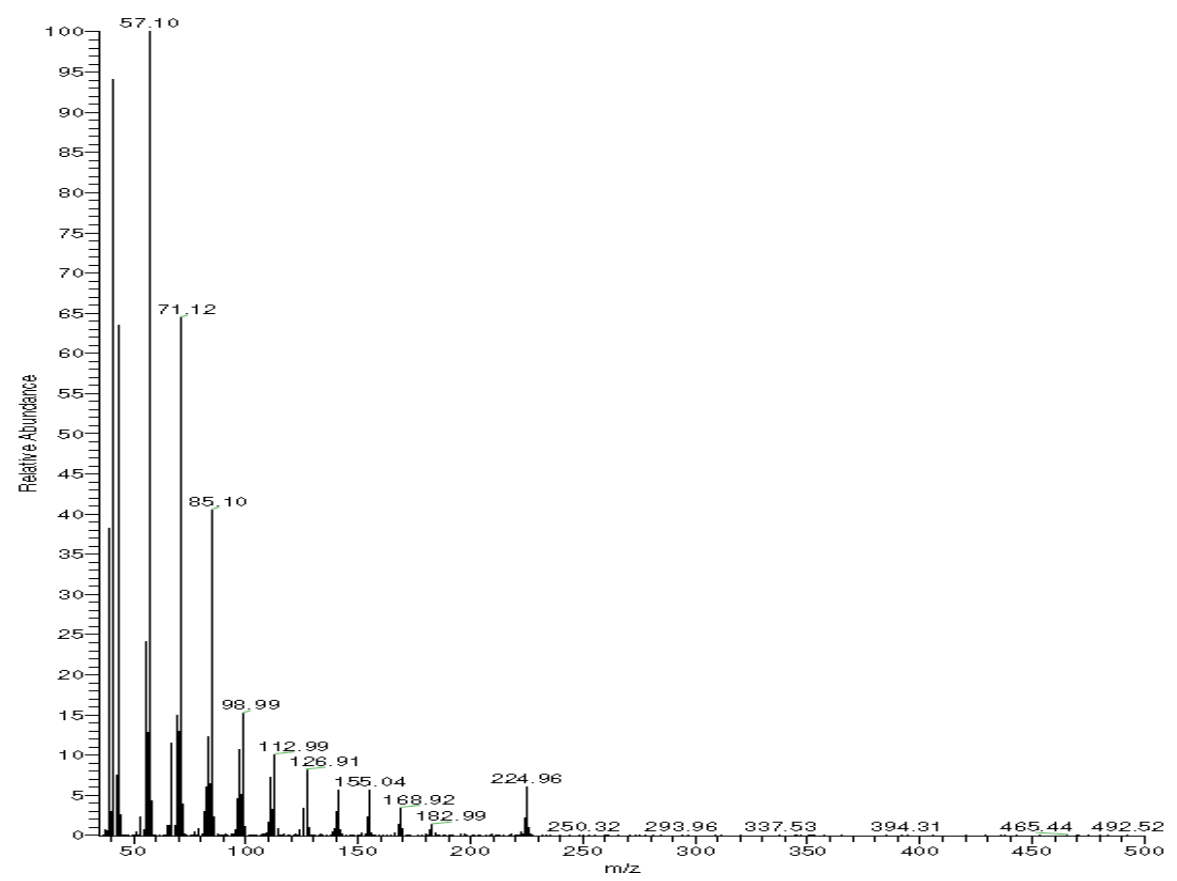

Figure 2: Mass spectrum of Tetradecane screened at ramp rate of $10{ }^{\circ} \mathrm{C} / \mathrm{min}$ and starting temperature of $100{ }^{\circ} \mathrm{C}(\mathrm{SC} 8$, Table 2) 
In a similar way, Eicosane has fragment 71 as second in abundance when screened at lower temperature but this fragment became third in abundance when high starting temperature were applied.

Table 4: Fragmentation pattern of DRO by 8 GC-MS screening conditions (SC 1 -SC 8)

\begin{tabular}{|c|c|c|c|c|c|c|c|c|}
\hline DRO & $\begin{array}{l}\mathrm{SC} 1(\mathrm{St}= \\
40^{\circ} \mathrm{C}, \mathrm{Rr}= \\
\left.5^{\circ} \mathrm{C} / \mathrm{min}\right)\end{array}$ & $\begin{array}{l}\mathrm{SC} 2(\mathrm{St}= \\
40^{\circ} \mathrm{C}, \mathrm{Rr}= \\
\left.10^{\circ} \mathrm{C} / \mathrm{min}\right)\end{array}$ & $\begin{array}{l}\mathrm{SC} 3(\mathrm{St}= \\
60{ }^{\circ} \mathrm{C}, \mathrm{Rr}= \\
\left.5{ }^{\circ} \mathrm{C} / \mathrm{min}\right)\end{array}$ & $\begin{array}{l}\mathrm{SC} 4(\mathrm{St}= \\
60^{\circ} \mathrm{C}, \mathrm{Rr}= \\
\left.10^{\circ} \mathrm{C} / \mathrm{min}\right)\end{array}$ & $\begin{array}{l}\mathrm{SC} 5(\mathrm{St}= \\
80{ }^{\circ} \mathrm{C}, \mathrm{Rr}= \\
\left.5^{\circ} \mathrm{C} / \mathrm{min}\right)\end{array}$ & $\begin{array}{l}\mathrm{SC} 6(\mathrm{St}= \\
80^{\circ} \mathrm{C}, \mathrm{Rr}= \\
\left.10^{\circ} \mathrm{C} / \mathrm{min}\right)\end{array}$ & $\begin{array}{l}\mathrm{SC} 7(\mathrm{St}= \\
100{ }^{\circ} \mathrm{C}, \mathrm{Rr}= \\
\left.5{ }^{\circ} \mathrm{C} / \mathrm{min}\right)\end{array}$ & $\begin{array}{l}\mathrm{SC} 8(\mathrm{St}= \\
100^{\circ} \mathrm{C}, \mathrm{Rr}= \\
\left.10^{\circ} \mathrm{C} / \mathrm{min}\right)\end{array}$ \\
\hline C10 & $\begin{array}{l}41,57,39,4 \\
3,71,85,99\end{array}$ & $\begin{array}{l}41,57 \\
43,39,71,8 \\
5,99\end{array}$ & $\begin{array}{l}41,57 \\
43,39,71,8 \\
5,99\end{array}$ & $\begin{array}{l}41,57,43,39, \\
71,85,99\end{array}$ & $\begin{array}{l}41,57,43,3 \\
9,71,85,99\end{array}$ & $\begin{array}{l}41,57,43,3 \\
9,71,85,99\end{array}$ & $\begin{array}{l}41,57,43,39 \\
71,85,99\end{array}$ & ND \\
\hline $\mathrm{C} 11$ & $\begin{array}{l}41,57,43,3 \\
9,71,85,99\end{array}$ & $\begin{array}{l}41,57,43,7 \\
1,39,85,99\end{array}$ & $\begin{array}{l}41,57, \\
43,39,71,8 \\
5,99\end{array}$ & $\begin{array}{l}41,57,43,(39 \\
, 71), 85,99\end{array}$ & $\begin{array}{l}41,57,43,3 \\
9,71,85,99\end{array}$ & $\begin{array}{l}41,57 \\
9,71),\end{array}$ & $\begin{array}{l}41,57,43, \\
71,39,85,99\end{array}$ & $\begin{array}{l}41,57,43,39 \\
71,85,99\end{array}$ \\
\hline $\mathrm{C} 12$ & $\begin{array}{l}41,57,43,7 \\
1,39,85,99\end{array}$ & $\begin{array}{l}41,57,43,7 \\
1,39,85,99\end{array}$ & $\begin{array}{l}41,57, \\
43,(39,71), \\
85,99\end{array}$ & $\begin{array}{l}41,57,43,71 \\
39,85,99\end{array}$ & $\begin{array}{l}41,57,43,7 \\
1,39,85,99\end{array}$ & $\begin{array}{l}41,57 \\
9,71)\end{array}$ & $\begin{array}{l}41,57,43, \\
71,39,85,99\end{array}$ & $\begin{array}{l}41,57,43,39 \\
71,85,99\end{array}$ \\
\hline $\mathrm{C} 13$ & $\begin{array}{l}41,57,43,7 \\
1,39,85,99\end{array}$ & $\begin{array}{l}41,57,4 \\
1,39,85\end{array}$ & $\begin{array}{l}41,57,43,7 \\
1,39,85,99\end{array}$ & $\begin{array}{l}41,57 \\
39,85\end{array}$ & $\begin{array}{l}41,57 \\
1,39\end{array}$ & $\begin{array}{l}7,43, \\
9, \\
9\end{array}$ & $\begin{array}{l}41,57,43, \\
71,39,85,99\end{array}$ & $\begin{array}{l}41,57,43, \\
71,39,85,99\end{array}$ \\
\hline C14 & $\begin{array}{l}41,57,43,7 \\
1,39,85,99\end{array}$ & $\begin{array}{l}41,57,43,7 \\
1,39,85,99\end{array}$ & $\begin{array}{l}41,57,43,7 \\
1,39,85,99\end{array}$ & $\begin{array}{l}41,57,43,71, \\
(39,85), 99\end{array}$ & $\begin{array}{l}41,57,43,7 \\
1,39,85,99\end{array}$ & $\begin{array}{l}41,57,43, \\
71,39 \\
85,99\end{array}$ & $\begin{array}{l}57,41,43, \\
71, \\
(39,85), 99\end{array}$ & $\begin{array}{l}57,41,43,71 \\
39,85,99\end{array}$ \\
\hline C15 & $\begin{array}{l}41,57 \\
(43,71), 85, \\
39,99\end{array}$ & $\begin{array}{l}57,41 \\
3,85,3\end{array}$ & $\begin{array}{l}41,57,43, \\
71, \\
(39,85), 99\end{array}$ & $\begin{array}{l}57,41,(43,71 \\
), 85,39,99\end{array}$ & $\begin{array}{l}57,41 \\
1,39,\end{array}$ & $\begin{array}{l}57,41,43,7 \\
1,85 \\
39,99\end{array}$ & $\begin{array}{l}(41,57),(43, \\
71), \\
39,85,99\end{array}$ & $\begin{array}{l}57,41,71,43 \\
85,39,99\end{array}$ \\
\hline C16 & $\begin{array}{l}57,41,71,4 \\
3,85,39,99\end{array}$ & $\begin{array}{l}57,41,71,4 \\
3,85,39,99\end{array}$ & $\begin{array}{l}57,41,43 \\
71,85 \\
39,99\end{array}$ & $\begin{array}{l}(41,57), 71,4 \\
3,85,39,99\end{array}$ & $\begin{array}{l}57,41,(43,7 \\
1),(39,85), \\
99\end{array}$ & $\begin{array}{l}57,41,71, \\
43,85 \\
39,99\end{array}$ & $\begin{array}{l}57,41,71, \\
43,85,39 \\
99\end{array}$ & $\begin{array}{l}57,41,71,43 \\
85,39,99\end{array}$ \\
\hline $\mathrm{C} 17$ & $\begin{array}{l}4 \\
9\end{array}$ & $\begin{array}{l}4 \\
9\end{array}$ & $\begin{array}{l}57,41,71,4 \\
3,85,39,99\end{array}$ & $\begin{array}{l}1,43, \\
9\end{array}$ & $\begin{array}{l}57,41, \\
71,43, \\
85,39,99\end{array}$ & $\begin{array}{l}57,41,71, \\
43,85 \\
39,99\end{array}$ & $\begin{array}{l}57,41,71,43 \\
85,39,99\end{array}$ & $\begin{array}{l}57,41,71,43 \\
85,39,99\end{array}$ \\
\hline $\mathrm{C} 18$ & $\begin{array}{l}57,41,71,4 \\
3,85,39,99\end{array}$ & $\begin{array}{l}57,71,41, \\
43,85,39,9 \\
9\end{array}$ & $\begin{array}{l}, 41,71,4 \\
35,39,99\end{array}$ & $\begin{array}{l}57,41,71,43 \\
85,39,99\end{array}$ & $\begin{array}{l}57,41, \\
71,43, \\
85,39,99\end{array}$ & $\begin{array}{l}57,41,71, \\
43,85 \\
39,99\end{array}$ & $\begin{array}{l}57,41,71,43 \\
85,39,99\end{array}$ & $\begin{array}{l}57,41,71,43 \\
85,39,99\end{array}$ \\
\hline C19 & $\begin{array}{l}57,41,71,4 \\
3,85,(39,99 \\
)\end{array}$ & $\begin{array}{l}57,71,41,(4 \\
3,85,)(39,9 \\
9)\end{array}$ & $\begin{array}{l}57,41,71,4 \\
3,85,39,99\end{array}$ & $\begin{array}{l}57,41,71,43 \\
85,39,99\end{array}$ & $\begin{array}{l}57,41, \\
71,43, \\
85,39,99\end{array}$ & $\begin{array}{l}57,41,71, \\
43,85 \\
39,99\end{array}$ & $\begin{array}{l}57,41,71,43 \\
85,39,99\end{array}$ & $\begin{array}{l}57,41,71,43 \\
85,39,99\end{array}$ \\
\hline C20 & $\begin{array}{l}57,71,41,(4 \\
3,85),(39,9 \\
9)\end{array}$ & $\begin{array}{l}57,71,41, \\
85,43,99,3 \\
9\end{array}$ & $\begin{array}{l}57,41,71,4 \\
3,85,39,99\end{array}$ & $\begin{array}{l}57,41,71,43 \\
85,39,99\end{array}$ & $\begin{array}{l}57,41, \\
71,43, \\
85,39,99\end{array}$ & $\begin{array}{l}57,41,71, \\
43,85 \\
39,99\end{array}$ & $\begin{array}{l}57,41,71,43 \\
85,39,99\end{array}$ & $\begin{array}{l}57,41,71,43 \\
85,39,99\end{array}$ \\
\hline $\mathrm{C} 21$ & $\begin{array}{l}57,71,41,8 \\
5,43,99,39\end{array}$ & $\begin{array}{l}57,71,41, \\
85,43,99,3 \\
9\end{array}$ & $\begin{array}{l}57,41,71,4 \\
3,85,39,99\end{array}$ & $\begin{array}{l}57,41,71,43 \\
85,39,99\end{array}$ & $\begin{array}{l}57,41, \\
71,43, \\
85,39,99\end{array}$ & $\begin{array}{l}57,41,71, \\
43,85 \\
39,99\end{array}$ & $\begin{array}{l}57,(41,71), 4 \\
3,85,39,99\end{array}$ & $\begin{array}{l}57,41,71,43 \\
85,39,99\end{array}$ \\
\hline $\mathrm{C} 22$ & $\begin{array}{l}57,71,41,8 \\
5,43,99,39\end{array}$ & $\begin{array}{l}57,71,41, \\
85,43,99,3 \\
9\end{array}$ & $\begin{array}{l}57,41,71,4 \\
3,85 \\
(39,99)\end{array}$ & $\begin{array}{l}57,71,41, \\
43,85,39,99\end{array}$ & $\begin{array}{l}57,41, \\
71,43, \\
85,39,99\end{array}$ & $\begin{array}{l}57,41,71, \\
43,85 \\
39,99\end{array}$ & $\begin{array}{l}57,71,41, \\
43,85,39,99\end{array}$ & $\begin{array}{l}57,41,71,43 \\
85,39,99\end{array}$ \\
\hline $\mathrm{C} 23$ & $\begin{array}{l}57,71,41,8 \\
5,43,99,39\end{array}$ & $\begin{array}{l}57,71,85,4 \\
1,43,99,39\end{array}$ & $\begin{array}{l}57, \quad 71,41 \\
43,85, \\
(39,99)\end{array}$ & $\begin{array}{l}57, \quad 71,41, \\
43,85,39,99\end{array}$ & $\begin{array}{l}57, \quad 71,41, \\
43, \\
99,(39,\end{array}$ & $\begin{array}{l}57,71,41, \\
43, \\
39,99\end{array}$ & $\begin{array}{l}57, \quad 71,41 \\
43,85,39,99\end{array}$ & $\begin{array}{l}57,41,71,43 \\
85,39,99\end{array}$ \\
\hline C24 & $\begin{array}{l}57,71,85,4 \\
1,43,99,39\end{array}$ & $\begin{array}{l}57,71,85,4 \\
1,43,99,39\end{array}$ & $\begin{array}{l}57,71,41, \\
(43,85,) \\
(39,99)\end{array}$ & $\begin{array}{l}57,71,41, \\
43,85,(39,99 \\
)\end{array}$ & $\begin{array}{l}57,71,41, \\
43,85,(39, \\
99)\end{array}$ & $\begin{array}{l}57,(41,71), \\
43, \quad 85, \\
39,99\end{array}$ & $\begin{array}{l}57,71,41, \\
43,85,99,39\end{array}$ & $\begin{array}{l}57,(41,71), 4 \\
3,85, \quad(39, \\
99)\end{array}$ \\
\hline
\end{tabular}




\begin{tabular}{|c|c|c|c|c|c|c|c|}
\hline $\mathrm{C} 25$ & $\begin{array}{l}57,71, \\
85,41 \\
43,99,39\end{array}$ & 1,43 & $\begin{array}{l}57,71,41, \\
(43,85), \\
(39,99)\end{array}$ & $\begin{array}{l}57, \quad 71,41, \\
(43,85),(39, \\
99)\end{array}$ & $\begin{array}{l}57,71,41, \\
85,43, \\
99,39\end{array}$ & $\begin{array}{l}57,71,41,( \\
43,85), \\
(39,99)\end{array}$ & $\begin{array}{ll}57, \quad 71,41, & 57, \quad 71,41, \\
(43,85),(39, & 43,85,99,39 \\
99) & \end{array}$ \\
\hline
\end{tabular}

NB The first fragment in each group is of $100 \%$ abundance.

Another effect of starting temperature was the non-detection of decane in the surrogate standard when starting temperature of $100{ }^{\circ} \mathrm{C}$ was used (Figures 3 and 4 ).

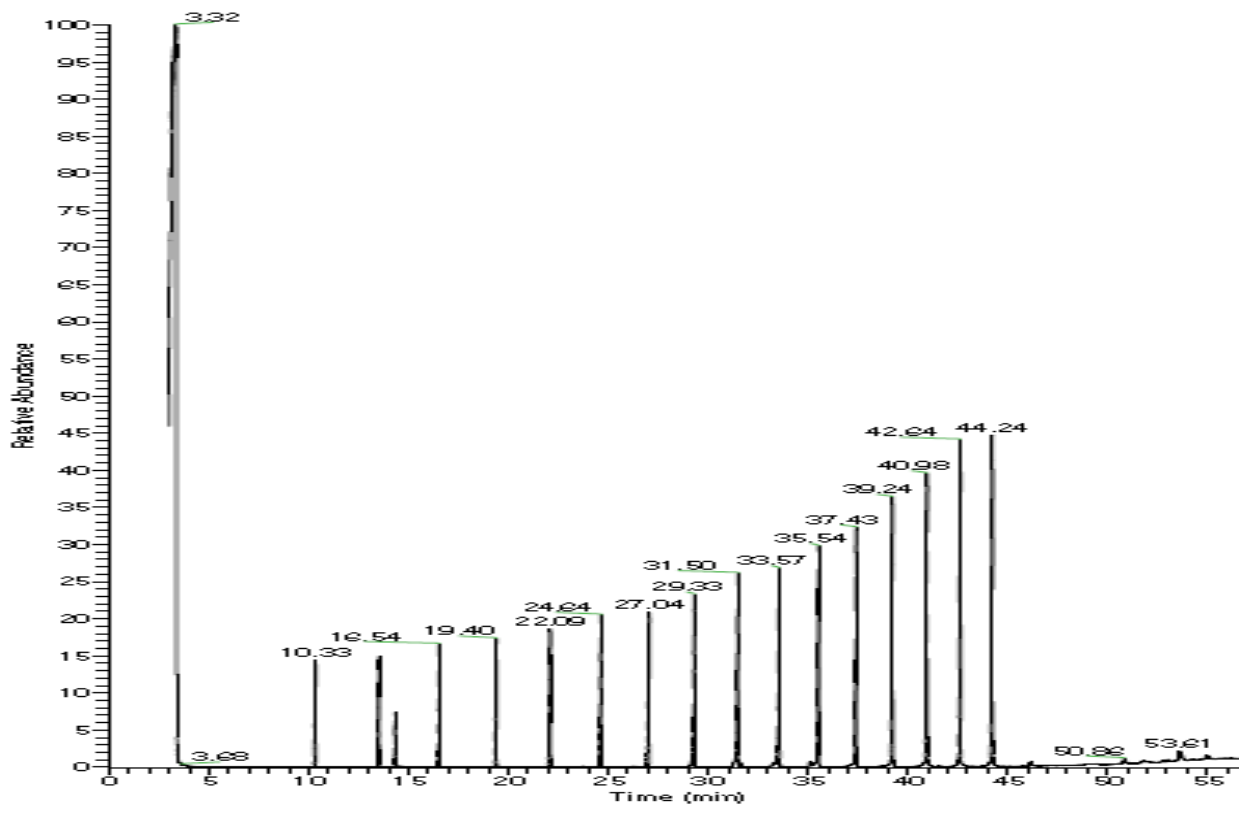

Figure 3: GC-MS chromatogram of $16 \mathrm{n}$ - alkane surrogate (SStd 1) screened at ramp rate of $5{ }^{\circ} \mathrm{C} / \mathrm{min}$. and starting temperature of $40{ }^{\circ} \mathrm{C}(\mathrm{Nb}$. The peaks at 3.32 and 14.32 are for solvent and internal standard respectively)

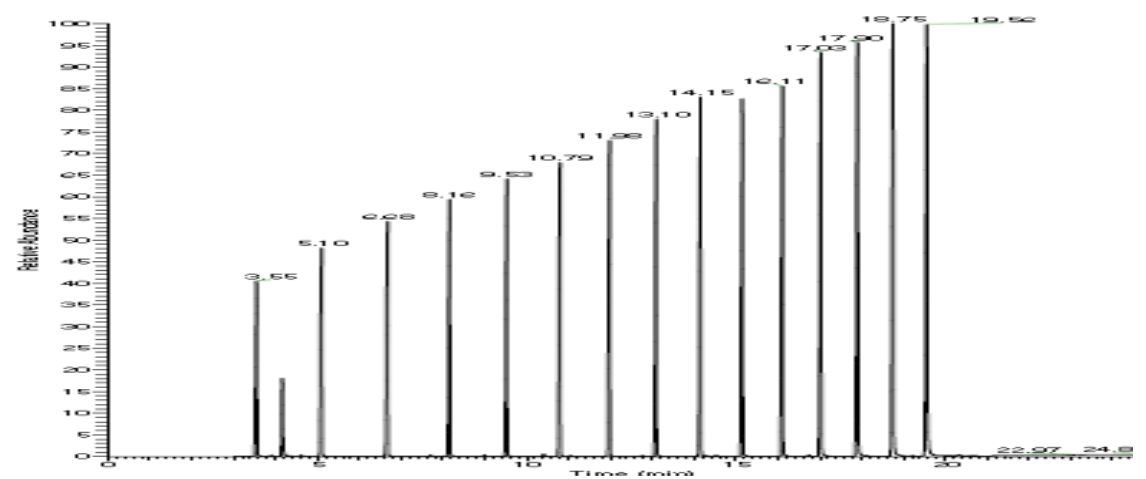

Figure 4: GC-MS chromatogram of the same n- alkane surrogate (SStd 1) screened at ramp rate of $10{ }^{\circ} \mathrm{C} / \mathrm{min}$. and starting temperature of $100{ }^{\circ} \mathrm{C}(\mathrm{Nb}$. The peak at 4.16 is for internal standard)

It was observed that in figure 4 , decane $(\mathrm{C} 10)$ was not captured by the mass spectrometer which could be attributed to the too high starting temperature. Therefore, this starting temperature may be too high for the analysis of DRO in environmental matrices if decade is one of the compounds in mind of the analysts to be qualified or quantified. It is pertinent to note that SStd 1 was certified to contain 16 DRO (i.e., C10 - C25) by Restek Plc, Bellefonte and the 
company's Mass spectrometric chromatogram for this surrogate standard solution contained exactly 16 peaks.

\section{Quantification of organic compounds by GC- MS methods}

The quantification of organic compounds in environmental matrices is based on the integration of the peak area or the peak ratio [18] since this quantity is in linear regression relationship with the concentration of the analytes. The procedure requires making a calibration curve (s) from known standard(s). Therefore, a poor or inefficient standard calibration has analytical implication on the quantification of the analyte. In this study, the effect of GC-MS screening conditions on the peak area and peak area ratio of DRO in the surrogate standard (SStd 1) was examined
(Table 5). It was observed that as the ramp rate or starting temperature changed, changes were observed in the peak areas for all the compounds analysed by the 8 GC-MS conditions. For instance, Dodecane (C12) has the PAR of 2.40 and 1.99 when screened by condition 1 (SC 1) and condition 2 (SC 2) respectively. The difference between these two screening conditions is the ramp rate. In both methods, the starting temperature was $40{ }^{\circ} \mathrm{C}$ but the ramp rate was changed from $5{ }^{\circ} \mathrm{C} / \mathrm{min}$. in (SC 1) to 10 ${ }^{\circ} \mathrm{C} / \mathrm{min}$. in condition 2 (SC 2 Table 2 ). Similarly, Cosane (C20) has PAR of 5.46 and 4.65 when screened at the same ramp rate of $5{ }^{\circ} \mathrm{C} /$ minute but different starting temperature of $60{ }^{\circ} \mathrm{C}$ and $100{ }^{\circ} \mathrm{C}$ respectively. In general, relative standard deviation of $\pm 6-11 \%$ was observed across the DRO from decane to pentacosane.

Table 5: The PAR of individual DRO in the surrogate standard (SStd 1) by the 8 different GC-MS screening conditions

\begin{tabular}{llllllllllll}
\hline DRO & SC 1 & SC 2 & SC 3 & SC 4 & SC 5 & SC 6 & SC 7 & SC 8 & & & \\
& PAR & PAR & PAR & PAR & PAR & PAR & PAR & PAR & AVE & STDEV & RSD \\
& & & & & & & & & PAR & & \\
C10 & 2.14 & 1.99 & 2.33 & 2.14 & 2.31 & 2.08 & ND & ND & 2.16 & 0.13 & 6.00 \\
C11 & 2.35 & 2.25 & 2.67 & 2.36 & 2.63 & 2.35 & 2.66 & 2.52 & 2.47 & 0.17 & 7.00 \\
C12 & 2.35 & 2.25 & 2.67 & 2.36 & 2.63 & 2.35 & 2.66 & 2.52 & 2.47 & 0.17 & 7.00 \\
C13 & 2.70 & 2.58 & 3.05 & 2.70 & 3.03 & 2.31 & 3.01 & 2.79 & 2.77 & 0.26 & 9.00 \\
C14 & 3.01 & 2.89 & 3.40 & 2.98 & 3.41 & 2.93 & 3.42 & 3.07 & 3.14 & 0.23 & 7.00 \\
C15 & 3.30 & 3.20 & 3.71 & 3.22 & 3.70 & 3.19 & 3.74 & 3.28 & 3.42 & 0.25 & 7.00 \\
C16 & 3.56 & 3.46 & 4.06 & 3.50 & 4.01 & 3.42 & 4.07 & 3.51 & 3.70 & 0.29 & 8.00 \\
C17 & 3.90 & 3.79 & 4.43 & 3.82 & 4.36 & 3.71 & 4.42 & 3.75 & 4.02 & 0.32 & 8.00 \\
C18 & 4.25 & 4.13 & 4.80 & 4.17 & 4.72 & 4.01 & 4.78 & 4.03 & 4.36 & 0.35 & 8.00 \\
C19 & 4.65 & 4.51 & 5.25 & 4.66 & 5.10 & 4.36 & 5.18 & 4.39 & 4.76 & 0.36 & 8.00 \\
C20 & 5.00 & 4.74 & 5.46 & 4.77 & 5.50 & 4.66 & 5.56 & 4.65 & 5.04 & 0.40 & 8.00 \\
C21 & 5.41 & 5.05 & 5.66 & 5.08 & 5.89 & 4.99 & 5.97 & 4.91 & 5.37 & 0.42 & 8.00 \\
C22 & 5.91 & 5.51 & 5.94 & 5.28 & 6.21 & 5.26 & 6.29 & 5.25 & 5.71 & 0.43 & 8.00 \\
C23 & 6.59 & 5.94 & 6.36 & 5.63 & 6.59 & 5.59 & 6.75 & 5.63 & 6.13 & 0.49 & 8.00 \\
C24 & 7.18 & 6.47 & 6.77 & 5.84 & 6.99 & 5.77 & 7.22 & 6.03 & 6.53 & 0.60 & 9.00 \\
C25 & 7.73 & 6.89 & 7.17 & 6.12 & 7.35 & 5.97 & 7.60 & 6.30 & 6.89 & 0.69 & 10.00
\end{tabular}

Effect of different GC-MS screening methods on the quantification of DRO in water and soil

\section{Standard calibration curves}

To quantify the amount of diesel in the polluted soil and water by the 8 GC-MS methods, 
standard solutions of the surrogate SStd 2 were made and 8 standard calibrations were drawn using Excel program version 2010. Table 6 present the correlation coefficients $\left(\mathrm{R}^{2}\right.$ values) and response factor and percentage of linearity of the standard curves.

Table 6 Correlation coefficient and percentage response of 8 GC-MS screening conditions on surrogate standard (SStd 2 )

\begin{tabular}{lccc}
\hline $\begin{array}{l}\text { GC-MS } \\
\text { Method }\end{array}$ & $\mathrm{R}^{2}$ values & $\begin{array}{c}\text { Response } \\
\text { factor }\end{array}$ & \% of correlation \\
\hline 1 (SC 1) & 0.9932 & 0.0045 & 99.32 \\
2 (SC 2) & 0.9870 & 0.0045 & 98.70 \\
3 (SC 3) & 0.9971 & 0.0040 & 99.71 \\
4 (SC 4) & 0.9810 & 0.0040 & 98.10 \\
5 (SC 5) & 0.9805 & 0.0039 & 98.05 \\
6 (SC 6) & 0.9722 & 0.0044 & 97.22 \\
7 (SC 7) & 0.9305 & 0.0034 & 93.05 \\
8 (SC 8) & 0.9224 & 0.0036 & 92.24 \\
\hline
\end{tabular}

In a perfect correlation between the PAR and concentration of the DRO, $\mathrm{R}^{2}$ value should be 1 . The percentage correlation or linearity was calculated from equation 5. The standard samples have been screened in the same batch at eight different screening conditions. The correlation coefficient $\left(\mathrm{R}^{2}\right)$ or percentage of linearity of the various standard calibration have indicated that GC-MS method 3 (SC 3) was the best condition for GC-MS screening of the DRO by this study. However the $\mathrm{R}^{2}$ values are in a narrow range of $0.922-0.997$ with average difference of 0.01

\section{Effect of different GC-MS screening Methods on the quantification of DRO in water}

The quantity of the selected DRO in diesel spiked de-ionized water was calculated by using the different calibration (linear) equations and compared to the theoretical value (Table 7).

Table 7 Concentrations of DRO in diesel spiked water by 9 GC-MS screening methods

\begin{tabular}{lcccc}
\hline GC-MS methods (SC) & $\mathrm{R}^{2}$ vaues & $\begin{array}{c}\text { TV of DRO } \\
(\mathrm{mg} / \mathrm{l})\end{array}$ & $\begin{array}{c}\text { EV of (DRO } \\
(\mathrm{mg} /)\end{array}$ & $\begin{array}{c}\text { \% diff.of EV } \\
\text { from TV }\end{array}$ \\
\hline 1 (SC 1) & 0.9932 & 927.52 & 878.73 & $5.26(<)$ \\
2 (SC 2) & 0.9870 & 927.52 & 1026.95 & $10.72(>)$ \\
3 (SC 3) & 0.9971 & 927.52 & 916.39 & $1.20(<)$ \\
5 (SC 4) & 0.9810 & 927.52 & 959.89 & $3.49(>)$ \\
6 (SC 6) & 0.9805 & 927.52 & 1006.73 & $8.54(>)$ \\
7 (SC 7) & 0.9722 & 927.52 & 1016.19 & $9.56(>)$ \\
8 (SC 8) & 0.9305 & 927.52 & 1185.42 & $27.81(>)$ \\
USEPA Method 8015B & 0.9224 & 927.52 & 1212.36 & $30.71(>)$ \\
\hline
\end{tabular}

$\mathrm{Nb} \mathrm{TV}$ and $\mathrm{EV}=$ theoretical and experimental values of the DRO in the water respectively, < or > indicates the $\mathrm{EV}$ is less than or greater than the theoretical values respectively 
The result obtained showed that no one of the GC-MS screening conditions (including the USEPA Method 8015B could exactly quantify the amount of DRO in the diesel spiked water. In chemical analyses for pollutants in environmental matrices it is not usually possible to achieve $100 \%$ extraction hence in some cases; a less values may be got. In other cases, the presence of impurity may lead to higher amount. This is the case with several analytical reports. In any case TNRCC1005 (11) recommended a difference of not greater than $25 \%$ in method verification. The result in Table 7 , showed that all the GC-MS screening conditions were within the limit of TNCC 1005(11) except condition SC 8 which gave verification difference far greater than the aforementioned limit. The difference could be trace to the calibration quality of this GC-MS screening method which as well gave the lowest $\mathrm{R}^{2}$ and percentage of linearity values. When the results accuracy were compared with regards to the theoretical values of the DRO in the spiked water, the USEPA method $8015 \mathrm{~B}$ gave the best result with a minor $1.05 \%$ differences between the theoretical and experimental DRO values. And as for the 8 developed methods, method 3 (SC 3) gave the closest result to the USEPA method $8015 \mathrm{~B}$ with a differences of $1.20 \%$ between the theoretical and experimental DRO values in the water samples (Table 7)

\section{Effect of different GC-MS screening methods on the quantification of DRO in soil}

Like the water analyses, similar quantification of the amount of the DRO in the diesel spiked soil samples was made. The results presented in table 8 shows that GC-MS screening methods have similar quantification of DRO in the soils as in water.

Table 8 Concentrations of the DRO in diesel spiked soil by 9 GC-MS screening methods

\begin{tabular}{lcccc}
\hline GC-MS methods & $\mathrm{R}^{2}$ values & $\begin{array}{l}\text { TV of } \\
(\mathrm{mg} / \mathrm{g})\end{array}$ & $\begin{array}{l}\text { EV of DRO } \\
(\mathrm{mg} / \mathrm{g})\end{array}$ & $\begin{array}{c}\text { diff.of } \\
\text { from TV }\end{array}$ \\
\hline 1 (SC 1) & 0.9932 & 862.02 & 783.92 & $9.06(<)$ \\
(SC 2) & 0.987 & 862.02 & 996.41 & $15.59(>)$ \\
3 (SC 3) & 0.9971 & 862.02 & 829.18 & $3.81(<)$ \\
(SC 4) & 0.981 & 862.02 & 899.26 & $4.32(>)$ \\
5 (SC 5) & 0.9805 & 862.02 & 957.36 & $11.06(>)$ \\
7 (SC 6) & 0.9722 & 862.02 & 943.48 & $9.45(>)$ \\
8 (SC 8) & 0.9305 & 862.02 & 1150.28 & $33.44(>)$ \\
USEPA Method 8015B & 0.9224 & 862.02 & 1161.66 & $34.76(>)$ \\
\hline
\end{tabular}

Again, the results showed that the GC-MS screening methods gave quantification of the DRO in the diesel spiked soil with differences from the theoretical values. However, method 1 - 6 (SC 1 - SC 6), have quantification differences within the TNRCC 1005 recommendation [11]. Methods 7 and 8 (SC7 \& SC 8) gave higher quantification and their percentage differences from the theoretical values were far greater than the recommended limit [11]. The reason for this may also be attributed to their low response factors as shown in Table 6. The high ramp rate or initial temperature of these methods may be the reasons for the low responsive calibration curves for the standard samples. Again, the USEPA method 8015B and method 3 (SC 3) gave the best results with differences of 1.87 and $3.81 \%$ respectively between the theoretical and experimental values of DRO in the diesel spiked soils 


\section{Conclusion}

Variation in the use of ramp rates and initial temperatures has been observed in the usage of GC-MS/FID for petroleum hydrocarbons analyses by analysts. The use of various starting temperatures and/or ramp rates could lead to significant difference in the results from a given laboratory analysis. Discrepancies in results on the same sample sent to different laboratories have been reported. The quest for better GC-MS screening conditions for the qualification and quantification of petroleum hydrocarbons in our environment called for this study. The results have shown that increase in ramp rate and/or initial temperature has analytical effects on GCMS analyses of the diesel range organics in particular and by extension hydrocarbons in general. Shorter throughput time in the analyses was obtained by increasing ramp rate or initial temperature but less accuracy for the quantification of DRO in soil and water. For the purpose of monitoring and regulating the concentration of DRO in the environment, initial temperature of $60{ }^{\circ} \mathrm{C}$ and ramp rate of $5{ }^{\circ} \mathrm{C} / \mathrm{min}$ is by this study buttressed. Furthermore, temperature had noticeable effects on the fragmentation patterns of compounds but concentration or sources of contaminants showed no significant effect on the fragmentation profile or on the retention time of DRO analysed at a specified initial temperature and ramp rate.

\section{Acknowledgement}

The correspondence author, Oghoje U. S wishes to acknowledge the entire staff of School of Chemistry, Bangor University, Bangor Gwynned, North Wales, United Kingdom, where this study was carried out particularly Dr Vera Thoss and the GC-MS Technicians, Tobby Pactrick, Mr Gwyver Glynne and Mr Nicholas. Furthermore, the authors are grateful to the Petroleum Technology Development Fund (PTDF) for partial funding of the Ph.D. project from which this publication is sought.

\section{References}

1. S. Guy, B. Eyal, and E. Gil (2012). Quantitative Analysis of Total Petroleum Hydrocarbons in Soils: Comparison between Reflectance Spectroscopy and Solvent Extraction by 3 Certified Laboratories. Applied and Environmental Soil Scienc. $1-11$.

2. J. E. Cortes, A. Suspes, S. Roa, C. González and H. E. Castro (2012). Total petroleum hydrocarbons by gas chromatography in Colombian waters and soils. American Journal of Environmental Science, 8 (4): 396 402.

3. US EPA (1995) Method 8015.

4. US EPA (1996) Method 8015B.

5. Z. Pawlak, T. Rauckyte and A. Oloyede (2008). Oil, grease and used petroleum oil management and environmental economic issues. Journal of Achievement in Materials and Manufacturing Engineering, 26 (1): 11 17.

6. Ferna'ndez, M D., JavierPro C. A. and Pablo-Aragonese, J. T. (2011). Terrestrial microcosms in a feasibility study on the remediation of dieselcontaminated soils. Ecotoxicology and Environmental Safety, 74: $2133-2140$

7. William G. (2007). Applying Novel GC Oven Technology to Increase Throughput in Analysis of Diesel Range Organics - Method 801. [Cited 2020 29th July]; from www.perkinelmer.com

8. Zenkevich, I. G. (2019). Homologous Increments of Gas Chromatographic Retention Indices as Characteristic of Organic Compounds Polarity. Russian Journal of General Chemistry 89(3):369-377

9. R. S. G. G' omez, T. Pandiyan, V. E. A. Iris, V. Luna-Pabello, and C. D. De Baz 'ua (2004). Spectroscopic determination of polyaromatic compounds in petroleum contaminated soils," Water, Air, and Soil Pollution. 158 (1): 137 151.

10. P. L. Wineman and R.O. Keto (1994). Target-compound method for the 
analysis of accelerant residues in fire debris. AnalyticaChimicaActa, 288: 97 $-110$

11. Texas Natural Recourse Conservation Commission (TNRCC), method 1005 (2001). Total petroleum hydrocarbons, Revision 03.

12. P. Paíga, L, Mendes, J. T. Albergaria, and C.M. Delerue-Matos (2012). Determination of total petroleum hydrocarbons in soil from different locations using infrared spectrophotometry and gas chromatography. [Cited 2020 10th April] from https://www.researchgate.net/publicatio $\mathrm{n} / 257908584$.

13. A. P. Schwab, J. Su , L. S. Wetze, S Pekarek and M . K. Banks (1999). Extraction of Petroleum Hydrocarbons from Soil by Mechanical Shaking. Environ. Sci. Technol., 33: 1940 - 1945.

14 T. Rauckyte, S. Żak, Z. Pawlak and A. Oloyede, (2010). Determination of Oil and Grease, Total Petroleum Hydrocarbons and Volatile Aromatic Compounds in Soil and Sediment Samples. Journal of Environmental Engineering and Landscape Management,18(3): 163 - 169.

15. US EPA 2003 Method 8015D.

16. US EPA 2007 Method 8015C.

17. X. Wang and R. Bartha (1990). Effects of bioremediation on residues, activity and toxicity in soil contaminated by fuel spills. Soil Biol. Biochem. 22: 501 505.

18. P. Seok-Un, K. Jong-Guk, J. Mi-Jeong, S. Byoung-Ju (2011). Source Identification of Atmospheric Polycyclic Aromatic Hydrocarbons in Industrial Complex Using Diagnostic Ratios and Multivariate Factor Analysis. Arch Environ Contam Toxicol. 60: 576-589.

19. V. I. Babushok, P. J. Linstrom, J. J. Reed, I. G. Zenkevich, R. L. Brown, W. G. Mallard, and S. E. Stein (2007). Development of A Database of Gas Chromatographic Retention Properties of Organic Compounds. Journal of Chromatography. 1157: $414-421$
20. J. P. Ausloos, C .L. Clifton, S. G. Lias, A. I. Mikaya, S. E. Stein, D. V. Tchekhovskoi, O. D. Sparkman, V. Zaikin, and D. Zhu (1999). 10: 287 299 (NIST Standard Reference Database 1A NIST/EPA/NIH Mass Spectral Library with Search Program. Data Version: NIST 05, 2005)

21 P. J. Linstrom, and W.G. Mallard (2005). NIST Chemistry WebBook, NIST Standard Reference Database Number 69, National Institute of Standards and Technology, Gaithersburg, MD, [Cited $202010^{\text {th }}$ April]from http://webbook.nist.gov/chemistry.

22. G. Petroselli, M. Kanti-Mandal, L. C. Chen, G. T. Ruiz, E. W. Kenzo-Hiraoka, H. Nonamid and R. Erra-Balsellsa (2012). Mass Spectrometry of Rhenium Complexes: A Comparative Study by Using LDI-MS, MALDI-MS, PESI-MS and ESI-MS Published online in Wiley Online Library, January 12, 2012, [Cited $2020 \quad 10^{\text {th }} \quad$ April] from www.wileyonlinelibrary.com, DOI 10.1002/jms.2965. 